\title{
Real life triplet FIr/FOx chemotherapy in first-line metastatic pancreatic ductal adenocarcinoma patients: recommended schedule for expected activity and safety and phase II study
}

\author{
Gemma Bruera ${ }^{1,2}$, Silvia Massacese ${ }^{3}$, Stefania Candria ${ }^{1}$, Antonio Galvano ${ }^{4}$, Rosa \\ Manetta $^{5}$, Aldo Victor Giordano ${ }^{5}$, Sergio Carducci ${ }^{5}$, Alessandra Di Sibio ${ }^{5}$, Eugenio \\ Ciacco $^{3}$, Antonio Russo ${ }^{4}$, Enrico Ricevuto ${ }^{1,2}$ and on behalf of Oncology Network \\ ASL1 Abruzzo, Italy \\ ${ }^{1}$ Oncology Territorial Care Unit, S. Salvatore Hospital, Oncology Network ASL1 Abruzzo, University of L'Aquila, L'Aquila, Italy \\ ${ }^{2}$ Department of Biotechnological and Applied Clinical Sciences, University of L'Aquila, L'Aquila, Italy \\ ${ }^{3}$ Pharmacy Unit, S. Salvatore Hospital, Oncology Network ASL1 Abruzzo, L'Aquila, Italy \\ ${ }^{4}$ Medical Oncology Unit, Department of Surgical, Oncological and Stomatological Sciences, University of Palermo, Palermo, Italy \\ ${ }^{5}$ Radiology Unit, S. Salvatore Hospital, Oncology Network ASL1 Abruzzo, L'Aquila, Italy \\ Correspondence to: Antonio Russo, email: antonio.russo@usa.net \\ Keywords: Flr/FOx; first-line; metastatic pancreatic ductal adenocarcinoma; phase II study; triplet chemotherapy \\ Received: March 29, $2018 \quad$ Accepted: July 18, $2018 \quad$ Published: August 07, 2018 \\ Copyright: Bruera et al. This is an open-access article distributed under the terms of the Creative Commons Attribution License 3.0 \\ (CC BY 3.0), which permits unrestricted use, distribution, and reproduction in any medium, provided the original author and source \\ are credited.
}

\section{ABSTRACT}

Background: Gemcitabine/nab-paclitaxel and FOLFIRINOX demonstrated significantly increased survival compared with gemcitabine in metastatic pancreatic ductal adenocarcinoma (PDAC): objective response rate (ORR) 23 and $31.6 \%$, progression-free survival (PFS) 5.5 and 6.4 months, overall survival (OS) 8.7 and 11.1 months. Present phase II study evaluated recommended first-line triplet FIr/FOx schedule.

Methods: Simon two-step design: $p_{0} 10 \%, p_{1} 30 \%$, power $80 \%, a 5 \%, \beta 20 \%$. Projected ORR: I step, 1/10; II 5/29. Schedule: 12h-timed-flat-infusion/5-fluorouracil 750-800-900 mg/m² d1-2,8-9,15-16,22-23; irinotecan 120-140-160 mg/m² d1,15; oxaliplatin $70-80 \mathrm{mg} / \mathrm{m}^{2} \mathrm{d8}, 22$; every 4 weeks, according to clinical parameters (age, comorbidities, performance status (PS), liver function). Activity and efficacy were evaluated, and compared using log-rank; limiting toxicity syndromes (LTS), using chi-square.

Results: Twenty-nine consecutive patients were enrolled, according to primary/ intermediate/secondary Cumulative Illness Rating Scale (CIRS). Median age 62; elderly 13 (44.7\%); PS2 3 (10.4\%), secondary CIRS 5 (17.2\%). Primary endpoint was met: ORR 53\% (7/13 patients) as-treated, 50\% intent-to-treat. Cumulative G3-4 toxicities: diarrhea $17 \%$, asthenia $14 \%$, hypertransaminasemy $7 \%$, mucositis $7 \%$, vomiting $3 \%$, anemia $3 \%$, thrombocytopenia $3 \%$. LTS were $27.5 \%$ overall, $38.4 \%$ in elderly. At 3 months median follow-up, PFS 4 months, OS 11 months. PS2 patients showed significantly worse OS $(P 0.022)$.

Conclusion: Intensive first-line triplet FIr/FOx is tolerable at modulated doses, and confirms high activity/efficacy in metastatic PDAC. Patients' careful selection, and exclusion of PS2, can maintain safety profile and efficient dose intensity. 


\section{INTRODUCTION}

Metastatic pancreatic ductal adenocarcinoma (PDAC) is a lethal disease with approximately 6 months median overall survival (OS) [1-3]. In the clinical evolution of metastatic PDAC, different combination treatment options have been evaluated, in order to increase clinical outcome. Gemcitabine was the only approved single agent, with median OS 5.7 months and 1-year OS rate $20 \%$ [1]. Gemcitabine $1000 \mathrm{mg} / \mathrm{m}^{2}$, administered over 30 minutes, weekly for 3 weeks every 28 days, was considered standard treatment schedule. Fixed-dose rate gemcitabine $\left(10 \mathrm{mg} / \mathrm{m}^{2} /\right.$ minute $)$ maximized intracellular concentrations of the phosphorylated active forms of gemcitabine, and may substitute standard infusion over 30 minutes $[4,5]$.

Even if phase III studies proposing gemcitabinebased associations failed to improve OS [6-16], excepting with erlotinib, a recent meta-analysis demonstrated that they achieved OS benefit in patients with good performance status (PS) [17]. Doublet gemcitabine-based associations with different drugs (cisplatin, oxaliplatin, fluoropyrimidine) reported objective response rate (ORR) ranging between $6.9-26.8 \%$, progression-free survival (PFS) 2.7-6.0 months, OS 5.7-9.0 months, but failed to significantly increase OS [6-11, 13, 15]: gemcitabine plus oxaliplatin (OXP) increased ORR, PFS and clinical benefit, with no OS benefit, as reported with fixed-dose rate gemcitabine and OXP; capecitabine increased ORR and PFS, with a trend toward increased OS. Patients with PS 0-1 have shown a favorable or potentially favorable impact of gemcitabine-based doublets on PFS or OS. Gemcitabine combinations with targeted agents (bevacizumab, cetuximab) did not improved OS (5.8 and 8.8 months, respectively) [18-20]. The EGFR tyrosine kinase inhibitor erlotinib added to gemcitabine significantly improved OS compared to gemcitabine alone: median OS 6.24 months and 1-year OS rate 23\%, with a significantly improved PFS, 3.75 months. More, bevacizumab addiction to this doublet chemotherapy significantly increased PFS 4.6 months, but not OS (7.1 months) [21]. Gemcitabine plus a platinum agent (i.e. cisplatin or OXP) could be also considered in patients with hereditary risk factors (BRCA 2 or PALB mutations).

The association of nab-paclitaxel to gemcitabine reported highest clinical benefit in patients with PDAC, and significantly raised up OS 8.7 months, PFS 5.5 months, and ORR $23 \%$, compared with gemcitabine alone [22, 23]. Intensive triplet FOLFIRINOX regimen significantly prolonged OS up to 11.1 months, PFS up to 6.4 months, ORR 31.6\%, compared to gemcitabine arm [24].

The most relevant issue limiting the feasibility of addition of more drugs in a chemotherapy combination is the proper design of the schedule assuring the balance between tolerability for individual patients and effective received dose intensity (DI) of each drug in order to obtain the expected efficacy of the combination. Intensive regimens based on triplet chemotherapy in MCRC, and FOLFIRINOX regimen in metastatic PDAC, frequently required proper clinical management of toxicity and treatment modulations due to moderate/severe toxicities $[24,25]$

Over the last 10 years, we developed triplet chemotherapy regimen according to FIr/FOx schedule, characterized by 12 -hour $\left(10^{\mathrm{PM}}\right.$ to $\left.10^{\mathrm{AM}}\right)$ timed-flatinfusion (TFI) 5-FU (TFI/5-FU), without leucovorin, associated to irinotecan (CPT-11) and OXP, according to a weekly alternating schedule, also added to bevacizumab $[26,27]$. FIr/FOx showed efficacy equivalent to other triplet schedules, such as FOLFOXIRI [28, 29], with a good tolerability profile $[30,31]$, as first-line treatment of metastatic colorectal cancer (MCRC) patients, with increased received 5-FU DI and lower rate of grade 3-4 neutropenia. Intensive triplet chemotherapy plus bevacizumab, according to FIr-B/FOx schedule, was equivalently safe and feasible in young-elderly patients, selected by favourable PS, and comorbidity status. The evaluation of limiting toxicity syndromes (LTS), multiple site (LTS-ms) or single site (LTS-ss), represented an innovative indicator of toxicity of the individual patient $[32,33]$. More, pharmacogenomic biomarkers of 5-FU, CPT-11 and/or OXP metabolism, could be evaluated to predict gastrointestinal toxicity in individual patients [34-36].

To further improve efficacy/tolerability ratio of triplet chemotherapy regimens in metastatic PDAC patients, the present phase II study proposes first-line $\mathrm{FIr} / \mathrm{FOx}$ association $[26,27]$ in clinical practice.

\section{RESULTS}

\section{Patient demographics}

From February 2011 to September 2016, 29 consecutive, unselected patients were enrolled (Table 1): Male/Female ratio, 15/14; median age, 62 years; 10 (34.4\%) young-elderly (yE) ( $\geq 65<75$ years), $3(10.3 \%)$ old-elderly (oE) patients ( $\geq 75$ years); World Health Organization (WHO) PS 0, 1, and 2, 16, 10, and 3 patients; Cumulative Illness Rating Scale (CIRS) [37] primary, intermediate, and secondary, in 10,14 , and 5 patients; metastatic disease metachronous in $2(6.8 \%)$ patients, synchronous in 27 (93.1\%) patients. Clinical diagnosis of PDAC was performed in 3 (10.3\%) patients, hystological/ cytological in 26 (89.6\%) patients; these 3 patients, with typical clinical/laboratory presentation, and abnormal CA19.9 increase, did not underwent biopsy due to clinical features, poor PS, abnormal liver functional test. Primary tumor location was: head 17 (58.6\%) patients, body 7 (24.1\%), tail $5(17.2 \%)$.

Metastatic sites: liver 18 patients (62\%), lung 2 (6.8\%), lymph nodes 22 (75.8\%), local recurrence 
Table 1: Patients' features

Total N. (\%)

No. of patients 29

Sex

Male/Female

$15 / 14$

Age, years

median

62

range

48-76

$\geq 65<75$ years

$10(34.4)$

$\geq 75$ years

$3(10.3)$

WHO Performance Status

0

$16(55.1)$

1

$10(34.4)$

2

$3(10.3)$

Cumulative Illness Rating Scale (CIRS)

primary

$10(34)$

intermediate

$14(48.2)$

secondary

$5(17.2)$

Metastatic disease

metachronous

$2(6.8)$

synchronous

$27(93.1)$

Diagnosis

clinical

$3(10.3)$

hystological/cytological

$26(89.6)$

Primary tumor

head

17 (58.6)

body

tail

$5(17.2)$

Sites of metastases

liver

$18(62)$

lung

$2(6.8)$

lymph nodes

$22(75.8)$

local

$2(6.8)$

cutaneous/subcutaneous tissue

$1(3.4)$

peritoneal carcinomatosis

$12(41.3)$

bone

$2(6.8)$

No. of involved sites

1

$2(6.8)$

$\geq 2$

$27(93.1)$

(Continued) 
Total N. (\%)

\begin{tabular}{lc}
\hline Single metastatic sites & - \\
liver & - \\
lung & $2(6.8)$ \\
lymph nodes & - \\
local & - \\
peritoneal carcinomatosis & - \\
bone & \\
Liver metastases & $1(3.4)$ \\
single & $17(58.6)$ \\
multiple & $1(3.4)$ \\
Previous adjuvant chemotherapy: & $1(3.4)$ \\
gemcitabine & $1(3.4)$ \\
Previous radiotherapy: & - \\
Radiotherapy alone & - \\
Radiotherapy + chemotherapy (5-Fluorouracil c.i.) & $1(3.4)$ \\
Radiotherapy + chemotherapy (Capecitabine) & \\
\hline
\end{tabular}

Abbreviations: WHO, World Health Organization; c.i., continous infusion.

2 (6.8\%), cutaneous/subcutaneous tissue 1 (3.4\%), peritoneal carcinomatosis $12(41.3 \%)$, bone $2(6.8 \%)$. Metastatic site was single in 2 patients $(6.8 \%)$, multiple in $27(93.1 \%)$. Single metastatic sites: lymph nodes 2 patients $(6.8 \%)$. Liver metastases were single in 1 patient (3.4\%), multiple in 17 (58.6\%).

Five patients underwent surgery of primary pancreatic tumor. One patient received adjuvant gemcitabine, 1 patient underwent radiotherapy associated with capecitabine.

Baseline CA19.9 measurement was normal in 3 patients, elevated in 26.

\section{Activity and efficacy}

In the first step, according to two-steps Simon's design [38], assuming as minimal interesting activity an ORR 10\% (1 OR among 10 enrolled patients), OR were 3 out of 10 enrolled patients, ORR $30 \%$ in the intent-to-treat (ITT) analysis, and 5 out of 10 evaluable patients, ORR $50 \%$ in the as-treated analysis.

The phase II study was performed among the projected 29 patients. In the intent-to-treat analysis, 14 patients were evaluable, 13 patients did not received at least 3 cycles of treatments, and 2 patients were ontreatment at data cut-off. OR were 7 out of 14 patients, ORR 50\% ( $\alpha 0.05, \mathrm{CI} \pm 27)$ (Table 2): 5 objective partial responses (35.7\%), 2 complete responses (14.2\%); 3 stable disease $(21.4 \%)$; 4 progressive disease $(28.5 \%)$. Disease control rate was $71.4 \%(\alpha 0.05, \mathrm{CI} \pm 24)$. In the as-treated analysis, 13 patients who received at least three cycles of treatment as planned were evaluable for activity (1 patient was evaluated after 2 cycles). OR were 7 out of 13 patients, ORR $53 \%(\alpha 0.05, \mathrm{CI} \pm 27): 5$ partial responses (38.4\%), 2 complete responses (15.3\%); 3 stable disease (23\%); 3 progressive disease $(23 \%)$. Disease control rate was $76.9 \%(\alpha 0.05, \mathrm{CI} \pm 23)$.

At median follow-up of 3 months (Figure 1), median PFS was 4 months (0-21): 26 events occurred and 3 patients $(10.3 \%)$ were progression-free. Median OS was 11 months (0-33): 24 events occurred and 5 patients (17.2\%) were alive. Among $13 \mathrm{yE} / \mathrm{oE}$ patients, median PFS was 4 months (1-21), median OS 5 months (1-33). PFS and OS were not significantly worse in elderly compared to non-elderly patients $(P=0.360$ and 0.235 , respectively) (Figure 2). Among the 16 patients treated with full standard dose, median PFS was 4 months (021), median OS 11 months (1-29+); among 13 patients treated with modulated doses due to age, comorbidities, PS, and/or abnormal liver function, PFS was 3 months (0-13), median OS 12 months (0-33). PFS and OS were not significantly worse in patients treated with reduced/ modulated drugs doses compared to patients treated with full standard doses $(P=0.380$ and 0.749 , respectively $)$ (Figure 2). Among the 3 PS 2 patients, median PFS was 1 month (1-3), median OS 1 month (1-3); among 26 PS 0-1 patients, median PFS was 4 months $(0-21)$, median OS 12 months (0-33). OS was significantly worse in PS 
Table 2: Activity and efficacy data

\begin{tabular}{|c|c|c|c|c|}
\hline & \multicolumn{2}{|c|}{ Intent-to-treat Analysis } & \multicolumn{2}{|c|}{ As-treated Analysis } \\
\hline & No & $\%$ & No & $\%$ \\
\hline Enrolled patients & 29 & 100 & 29 & 100 \\
\hline Evaluable patients & 14 & 48.2 & 13 & 44.8 \\
\hline Objective Response & 7 & $50(\mathrm{CI} \pm 27)$ & 7 & $53(\mathrm{CI} \pm 27)$ \\
\hline Partial Response & 5 & 35.7 & 5 & 38.4 \\
\hline Complete Response & 2 & 14.2 & 2 & 15.3 \\
\hline Stable Disease & 3 & 21.4 & 3 & 23 \\
\hline Progressive Disease & 4 & 28.5 & 3 & 23 \\
\hline Median Progression-free Survival, months & 4 & & & \\
\hline Range & $0-21$ & 89.6 & & \\
\hline Progression events & 26 & & & \\
\hline Median Overall Survival, months & 11 & & & \\
\hline Range & $0-33$ & 82.7 & & \\
\hline Deaths & 24 & & & \\
\hline
\end{tabular}

2 compared with $0-1$ patients $(P=0.022)$; PFS was not significantly different $(P=0.078)$ (Figure 2$)$.

Among the 17 patients with head tumor location, median PFS was 4 months (0-13), median OS 11 months (0-33); among 12 patients with other than head pancreatic tumor locations, median PFS was 2 months (0-21), median OS 3 months (0-25). PFS and OS were not significantly different $(P=0.896)$, even if OS was trendy worse in patients with other than head pancreatic tumor location (Figure 2). Among the 18 patients with liver metastases, median PFS was 3 months (0-21), median OS 5 months (0-33); among 11 patients with other metastatic sites, median PFS was 4 months (0-12), median OS 11 months $(0-29+)$. PFS and OS were not significantly different $(P$ $=0.601$, and 0.869 , respectively), even if OS was trendy worse in patients with liver metastases (Figure 2).

Ten patients (34.4\%) received, at least, a second line treatment: FIr/FOx re-challenge in 1 patient (3.4\%); gemcitabine/nab-paclitaxel association in 8 patients (27.5\%); intra-arterial chemotherapy in 1 patient $(3.4 \%)$. Two patients $(6.8 \%)$ received a third line treatment: gemcitabine in 1 patient $(3.4 \%)$; capecitabine in 1 patient $(3.4 \%)$.

All evaluable patients with an increased Ca19.9 baseline value had a $>20 \%$ decrease: $58 \% \geq 50 \%$ decrease, $42 \% \geq 70 \%$ and $90 \%$ decrease. CA19-9 levels were not significantly correlated with PFS and OS.

\section{Dose-intensity} $1-11)$.
Median received dose intensities (rDI) per cycle were: 5-FU $1268.5(375-1800) \mathrm{mg} / \mathrm{m}^{2} / \mathrm{w}, 70.4 \%$ of projected-DI (pDI); CPT-11 $56(30-80) \mathrm{mg} / \mathrm{m}^{2} / \mathrm{w}, 70 \%$; OXP 29 (11-40) mg/m²/w, 72.5\% (Table 3). Median rDI per patient were: 5-FU $1484.25(375-1800) \mathrm{mg} / \mathrm{m}^{2} / \mathrm{w}$, $82.4 \%$ of pDI; CPT-11 63.25 (30-80) mg/m²/w, 79\%; OXP $33.5(0-40) \mathrm{mg} / \mathrm{m}^{2} / \mathrm{w}, 83.75 \%$. In yE patients, median rDIs per cycle were: 5 -FU $1500(375-1800) \mathrm{mg} / \mathrm{m}^{2} / \mathrm{w}, 83.3 \%$ of pDI; CPT-11 64 (30-80) mg/m²/w, 80\%; OXP 34 (11-40) $\mathrm{mg} / \mathrm{m}^{2} / \mathrm{w}, 85 \%$.

\section{Toxicity}

Table 4 describes cumulative toxicities in 29 enrolled patients, and 100 administered cycles. Cumulative G3-5 toxicities, by patients, were: diarrhea 5 patients $(17 \%)$, stomatitis/mucositis $2(6 \%)$, asthenia $4(14 \%)$, nausea $1(3 \%)$, vomiting $1(3 \%)$, hypoalbuminemia $1(3 \%)$, hypokalaemia $2(7 \%)$, hypertransaminasemia $2(7 \%)$, hyperbilirubinemia $1(3 \%)$, hypercreatininemia $1(3 \%)$, anemia $1(3 \%)$, neutropenia $5(17 \%)$, thrombocytopenia $1(3 \%)$. The prevalent limiting toxicities (LT) were diarrhea, asthenia, neurotoxicity, thrombocytopenia. Cumulative $\mathrm{G} 2$ toxicities, by patients, were: nausea 10 (34\%), vomiting $2(7 \%)$, diarrhea $9(31 \%)$, stomatitis/ mucositis $4(14 \%)$, hypoalbuminemia $2(7 \%)$, asthenia $10(34 \%)$, neurotoxicity $2(7 \%)$, hypokalaemia $1(3 \%)$, hypertransaminasemia $4(14 \%)$, hyperbilirubinemia $1(3 \%)$, anemia $3(10 \%)$, neutropenia $6(21 \%)$, thrombocytopenia $1(3 \%)$. One case of toxic death $(3 \%)$, due to G5 diarrhea, G4 mucositis, G4 thrombocytopenia, G3 anemia, associated to G3 hypoalbuminemia, G3 
hypokaliemia, G3 hypercreatinemia, G3 neutropenia, and G2 asthenia, was observed. Five out of 29 patients (17\%) discontinued FIr/FOx treatment due to limiting toxicity (neurotoxicity in 2 patients, asthenia in 1 , thrombocytopenia in 1 , toxic death in 1 ).

Overall, LTS were observed in 8 patients $(27.5 \%)$ (Table 5), 5 out of $13 \mathrm{yE} / \mathrm{oE}$ patients (38.1\%): $1(3.4 \%)$ LTS-ss, and $7(24.1 \%)$ LTS-ms. LTS-ms, consisting of a LT associated to other, at least G2, non-limiting toxicities were detected in 6 patients $(20.6 \%) ; \geq 2$ LTs in 1 patient (3.4\%). LTS were not significantly represented by LTS-ms compared to LTS-ss. The 1 LTS-ss was characterized by G3 diarrhea.

The 6 LTS-ms, consisting of LT associated to other, at least G2, non-limiting toxicities, were characterized by (Table 6): G2 neurotoxicity associated with G2 nausea,
G2 vomiting, G2 diarrhea, G2 asthenia, G2 neutropenia; G2 thrombocytopenia associated with G2 asthenia, G3 leuconeutropenia, G2 ipokaliemia, G2 hypoalbuminemia, G2 hypertansaminasemia, G2 asthenia, G2 anorexia; G2 thrombocytopenia associated with G2 diarrhea, G2 neutropenia, G2 alopecia, G2 hypertransaminasemia; G3 asthenia associated with G3 alopecia and G3 leuconeutropenia; G2 neurotoxicity associated with G2 nausea, G2 diarrhea, G2 constipation, G2 alopecia, G2 hypertransaminasemia, G3 neutropenia; G3 diarrhea associated with G2 nausea, G2 anorexia. LTS-ms, with double/more LTs, was reported in 1 patient $(3.4 \%)$ and characterized by G5 diarrhea, G4 mucositis, G4 thrombocytopenia and G3 anemia associated with G2 asthenia, G3 hypoalbuminemia, G3 hypokaliemia, G3 hypercreatininemia, G3 leuconeutropenia.

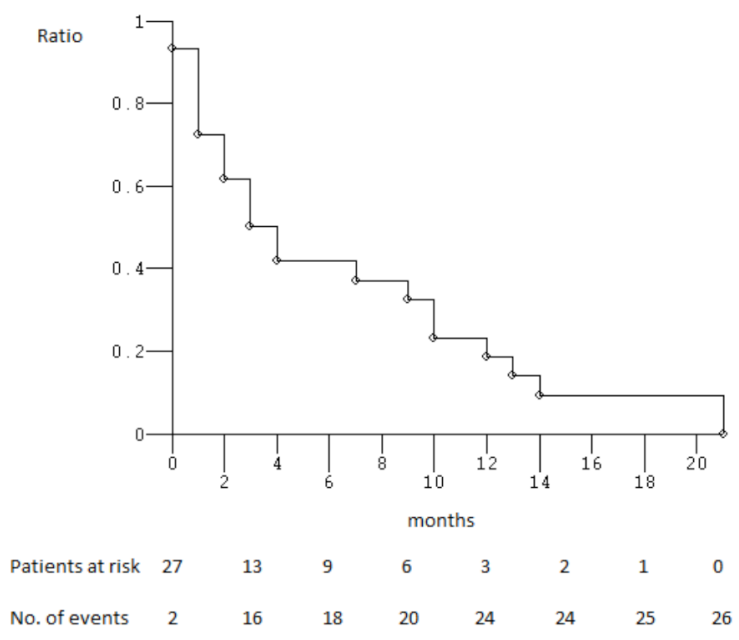

(A) 4 months (0-21)

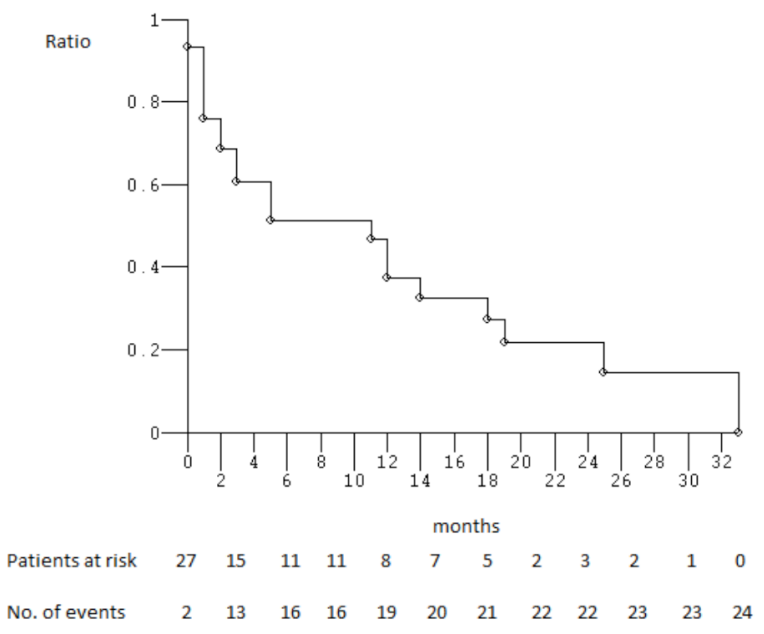

(B) 11 months (0-33)

Figure 1: Kaplan-Meier survival estimates. Overall enrolled patients; (A) progression-free survival; (B) overall survival. 


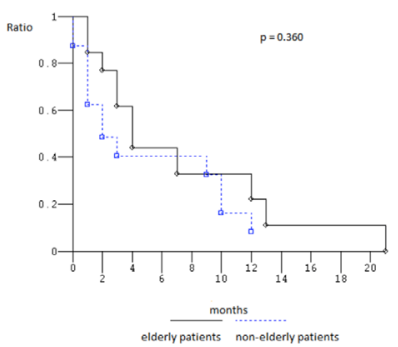

(A1)

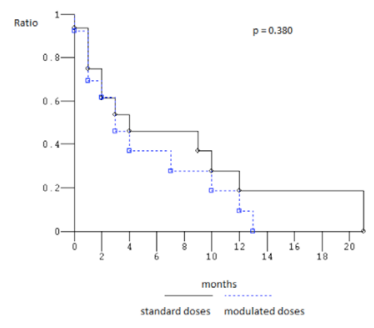

(A2)

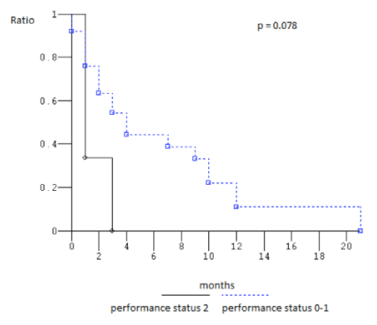

(A3)

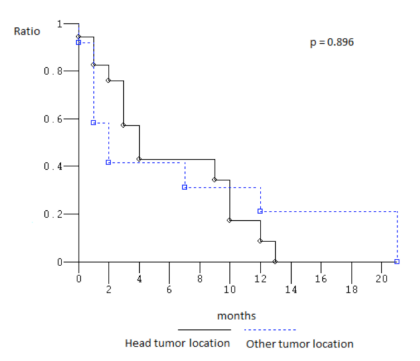

(A4)

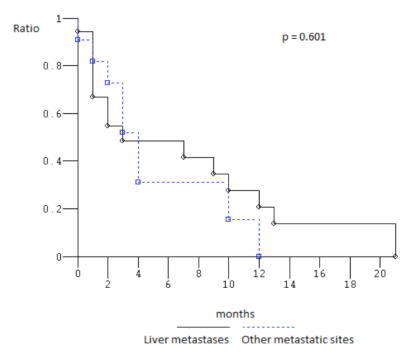

(A5)

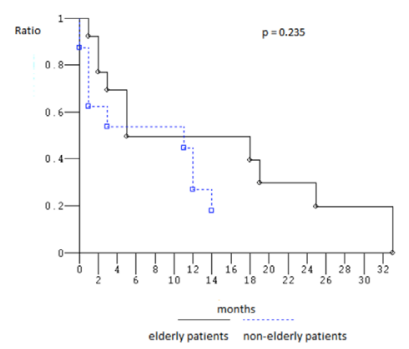

(B1)

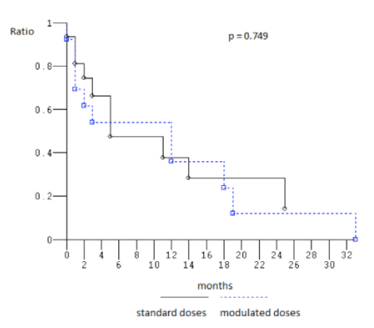

(B2)

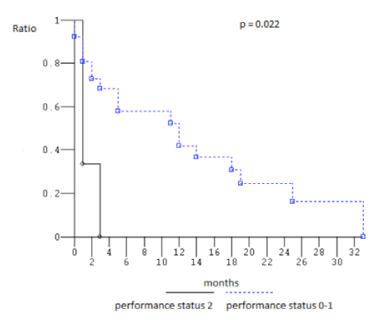

(B3)

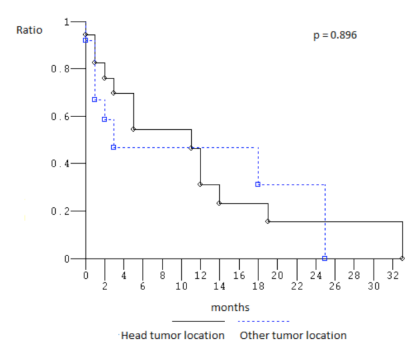

(B4)

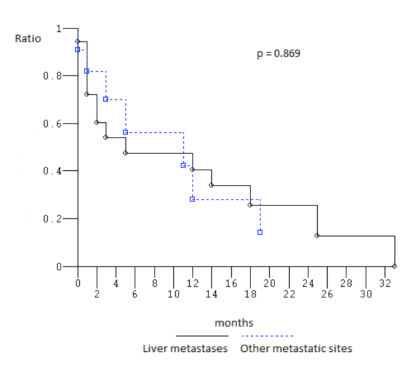

(B5)

Figure 2: Kaplan-Meier survival estimates. 1, Elderly compared to non-elderly patients; 2, patients treated with standard dose compared to patients treated with modulated doses; 3 , performance status 2 compared to $0-1$ patients; 4 , head compared to other tumor location; 5, liver metastases compared with other metastatic site; (A) progression-free survival; (B) overall survival. 


\begin{tabular}{|c|c|c|c|c|c|}
\hline & \multirow[b]{3}{*}{$\begin{array}{c}\text { Projected DI } \\
\mathrm{mg} / \mathrm{m}^{2} / \mathbf{w}\end{array}$} & \multicolumn{2}{|c|}{ All patients } & \multicolumn{2}{|c|}{ Young-elderly patients } \\
\hline & & \multicolumn{2}{|c|}{$\mathrm{DI} / \mathrm{cycle} \mathrm{mg} / \mathrm{m}^{2} / \mathrm{w}$} & \multicolumn{2}{|c|}{$\mathrm{DI} / \mathrm{cycle} \mathrm{mg} / \mathrm{m}^{2} / \mathrm{w}$} \\
\hline & & $\begin{array}{l}\text { Median } \\
\text { (Range) }\end{array}$ & $\begin{array}{c}\text { Received DI } \\
(\%)\end{array}$ & $\begin{array}{l}\text { Median } \\
\text { (Range) }\end{array}$ & $\begin{array}{c}\text { Received DI } \\
(\%)\end{array}$ \\
\hline 5-FU & 1800 & $\begin{array}{c}1268.5 \\
(375-1800)\end{array}$ & 70.4 & $\begin{array}{c}1500 \\
(375-1800)\end{array}$ & 83.3 \\
\hline CPT-11 & 80 & $\begin{array}{c}56 \\
(30-80)\end{array}$ & 70 & $\begin{array}{c}64 \\
(30-80)\end{array}$ & 80 \\
\hline OXP & 40 & $\begin{array}{c}29 \\
(11-40)\end{array}$ & 72.5 & $\begin{array}{c}34 \\
(11-40)\end{array}$ & 85 \\
\hline
\end{tabular}

Abbreviations: DI, dose-intensity; 5-FU, 5-fluorouracil; CPT-11, irinotecan; OXP, oxaliplatin.

\section{DISCUSSION}

Triplet chemotherapy according to FIr/FOx schedule met projected high activity as first-line treatment of metastatic PDAC patients, reaching the first step of activity according to Simon-two step design: ORR 50\% in the intent-to-treat and $53 \%$ in the as-treated analysis, with PFS 4 months (10.3\% of patients progression-free > 12 months), and OS 11 months (27.5\% of patients alive $>12$ months), in the preliminary analysis of efficacy. Activity and clinical outcome of FIr/FOx exceeded that reported with gemcitabine: median OS 5.7 months, and 1-year OS rate 20\%, median PFS 2.08 months, ORR 5.4\% $[1,2]$. Activity and clinical outcome may be higher than those reported with first generation gemcitabine-based combinations, excluding nab-paclitaxel: ORR 6.9-26.8\%, median PFS 2.7-6 months, median OS 5.7-9 months [5$16]$.

Recently, phase III trials evaluating more intensive first-line chemotherapy regimen, such as gemcitabine plus nab-paclitaxel and triplet FOLFIRINOX, demonstrated to be much more, and equivalently effective, with significantly increased survival benefit over standard gemcitabine alone in metastatic PDAC patients [24]: ORR $23 \%$ and $31.6 \%$, median PFS 5.5 and 6.4 months, OS 8.7 and 11.1 months, respectively. In the FOLFIRINOX study, median OS was significantly prolonged up to 11.1 months, with an increase of 4.3 months, compared with 6.8 months in the gemcitabine arm (hazard ratio for death, 0.57; $P<0.001$ ) [24]. OS rate at 12 months was $48.4 \%$, compared with $20.6 \%$ in the gemcitabine arm. In the recently reported phase III trial proposing gemcitabine and nab-paclitaxel association, 12-months OS rate was 35\% [23]. Activity and clinical data reported with FIr/FOx in the present study are in the range of those reported with conventional intensive first-line treatment in PDAC patients. Thus, more active first-line treatment of metastatic PDAC can contribute to increase efficacy. FIr/FOx schedule may increase activity and efficacy of metastatic PDAC, with clinical outcome overlapping that reported with other triplet chemotherapy schedules, and evaluated in phase III randomized trials, as previously reported in MCRC setting [26, 27].

Our present real life study on consecutive, unselected patients showed that 13 patients (44.8\%) were not evaluable in the ITT analysis because they did not received at least 3 cycles of treatment, thus confiming that, even today, the primary challenge of clinical management of metastatic PDAC patients is to start and safely perform at least 3 cycles of intensive chemotherapy treatment, to evaluate activity contributing to increase clinical outcome.

Among patients treated with intensive triplet FIr/FOx regimen, PFS and OS were not significantly different among patients treated with modulated and standard drug dosage, due to clinical parameters requiring treatment modulations. PS 2 significantly affected worse OS ( 1 compared with 12 months, $P=0.022$ ), thus confirming overall benefit in clinical outcome achieved by metastatic PDAC patients with PS $0-1$, treated with gemcitabine-based combinations [17]. In the MPACT trial, PS, presence of liver metastases, age, and number of metastatic sites involved were independent prognostic factors for OS and PFS [39, 40]. In our present study, PFS and OS seemed not significantly different according to primary tumor location (head or not), nor according to liver or other metastatic site, even if the small number of enrolled patients limited the relevance of subgroup analyses.

Median rDIs were $>80 \%$ of the projected dose for each drug, also in elderly patients. Cumulative G3-5 toxicities were prevalently represented by: diarrhea $(17 \%)$, stomatitis/mucositis (6\%), asthenia (14\%), nausea $(3 \%)$, vomiting $(3 \%)$, hypoalbuminemia $(3 \%)$, hypokalaemia (7\%), hypertransaminasemia (7\%), hyperbilirubinemia (3\%), hypercreatininemia (3\%), anemia $(3 \%)$, neutropenia $(17 \%)$, thrombocytopenia $(3 \%)$. In the previously reported phase II trial proposing intensive first-line triplet chemotherapy 
Table 4: Cumulative toxicity

\begin{tabular}{|c|c|c|c|c|c|c|c|c|c|c|}
\hline \multirow{3}{*}{$\frac{\text { Number }}{\text { NCI-CTC Grade }}$} & \multicolumn{5}{|c|}{ Patients } & \multicolumn{5}{|c|}{ Cycles } \\
\hline & \multicolumn{5}{|c|}{29} & \multicolumn{5}{|c|}{100} \\
\hline & 1 & 2 & 3 & 4 & 5 & 1 & 2 & 3 & 4 & 5 \\
\hline Nausea (\%) & $5(17)$ & $10(34)$ & $1(3)$ & - & - & $31(31)$ & $13(13)$ & $1(1)$ & - & - \\
\hline Vomiting (\%) & $10(34)$ & $2(7)$ & $1(3)$ & - & - & $15(15)$ & $3(3)$ & $1(1)$ & - & - \\
\hline Anorexia (\%) & $10(34)$ & $1(3)$ & $1(3)$ & - & - & $15(15)$ & $3(3)$ & $1(1)$ & - & - \\
\hline Diarrhea (\%) & $5(17)$ & $9(31)$ & $4(14)$ & - & $1(3)$ & $\begin{array}{c}38 \\
(20.5)\end{array}$ & $14(18)$ & $4(15)$ & - & $1(1)$ \\
\hline Hypoalbuminemia (\%) & - & $2(7)$ & $1(3)$ & - & - & - & $2(2)$ & $1(1)$ & - & - \\
\hline Constipation (\%) & $7(24)$ & $7(24)$ & $1(3)$ & - & - & $11(11)$ & $7(7)$ & $1(1)$ & - & - \\
\hline $\begin{array}{l}\text { Stomatitis/mucositis } \\
(\%)\end{array}$ & $7(24)$ & $4(14)$ & $1(3)$ & $1(3)$ & - & $16(16)$ & $5(5)$ & $1(1)$ & $1(1)$ & - \\
\hline Erythema (\%) & $1(3)$ & - & - & - & - & $1(1)$ & - & - & - & - \\
\hline Asthenia (\%) & $10(34)$ & $10(34)$ & $4(14)$ & - & - & $64(64)$ & $17(17)$ & $4(4)$ & - & - \\
\hline Neurotoxicity (\%) & $15(52)$ & $2(7)$ & - & - & - & $61(61)$ & $4(4)$ & - & - & - \\
\hline Hypertension (\%) & $1(3)$ & - & - & - & - & $2(2)$ & - & - & - & - \\
\hline Hypotension (\%) & - & - & - & - & - & - & - & - & - & - \\
\hline Gengivitis (\%) & - & - & - & - & - & - & - & - & - & - \\
\hline Rhinitis (\%) & $3(10)$ & - & - & - & - & $3(3)$ & - & - & - & - \\
\hline Epistaxis (\%) & $4(14)$ & - & - & - & - & $4(4)$ & - & - & - & - \\
\hline HFS (\%) & - & - & - & - & - & - & - & - & - & - \\
\hline Hyponatriemia (\%) & $1(3)$ & - & - & - & - & $1(1)$ & - & - & - & - \\
\hline Hypokalemia (\%) & $1(3)$ & $1(3)$ & $2(7)$ & - & - & $1(1)$ & $2(2)$ & $2(2)$ & - & - \\
\hline $\begin{array}{l}\text { Hypertransaminasemy } \\
(\%)\end{array}$ & $7(24)$ & $4(14)$ & $2(7)$ & - & - & $24(24)$ & $6(6)$ & $2(2)$ & - & - \\
\hline $\begin{array}{l}\text { Hyperpigmentation } \\
(\%)\end{array}$ & - & - & - & - & - & - & - & - & - & - \\
\hline $\begin{array}{l}\text { Fever without } \\
\text { infection (\%) }\end{array}$ & $2(7)$ & - & - & - & - & $2(2)$ & - & - & - & - \\
\hline Alopecia (\%) & $3(10)$ & $5(17)$ & $1(3)$ & - & - & $8(8)$ & $8(8)$ & $6(6)$ & - & - \\
\hline $\begin{array}{l}\text { Hyperbilirubinemia } \\
(\%)\end{array}$ & $2(7)$ & $1(3)$ & $1(3)$ & - & - & $2(2)$ & $1(1)$ & $1(1)$ & - & - \\
\hline $\begin{array}{l}\text { Hypercreatininemia } \\
(\%)\end{array}$ & - & - & $1(3)$ & - & - & - & - & $1(1)$ & - & - \\
\hline Anemia (\%) & $5(17)$ & $3(10)$ & $1(3)$ & - & - & $13(13)$ & $4(4)$ & $1(1)$ & - & - \\
\hline Leucopenia (\%) & $3(10)$ & $3(10)$ & $4(14)$ & - & - & $4(4)$ & $7(7)$ & $5(5)$ & - & - \\
\hline Neutropenia (\%) & - & $6(21)$ & $5(17)$ & - & - & - & $13(13)$ & $9(9)$ & - & - \\
\hline Thrombocytopenia (\%) & $1(3)$ & $1(3)$ & - & $1(3)$ & - & $5(5)$ & $1(1)$ & - & $1(1)$ & - \\
\hline
\end{tabular}

Abbreviations: NCI-CTC, National Cancer Institute Common Toxicity Criteria. 
Table 5: Limiting Toxicity Syndromes (LTS): overall and in elderly patients

\begin{tabular}{lcccccc}
\hline & \multicolumn{2}{c}{ Overall } & & \multicolumn{3}{c}{ Elderly } \\
\cline { 2 - 3 } \cline { 5 - 6 } & N. & \% & & N. & \% \\
\hline Patients & 29 & 100 & & 13 & 100 \\
Limiting Toxicity Syndromes (LTS) & 8 & 27.5 & & 5 & 38.4 \\
LTS single-site (LTS-ss) & 1 & 3.4 & & - & - \\
LTS multiple-sites (LTS-ms) & 7 & 24.1 & & 5 & 38.4 \\
$\quad$ Single LT plus G2-3 & 6 & 20.6 & & 4 & 30.7 \\
Double LTs & 1 & 3.4 & & 1 & 7.6 \\
\hline
\end{tabular}

Abbreviations: LT, limiting toxicity; G, grade.

plus bevacizumab according to FIr-B/FOx regimen, as first-line treatment in MCRC patients, cumulative G3-4 toxicities were similar: diarrhea (28\%), stomatitis/ mucositis (6\%), asthenia (6\%), hypertension (2\%), hypertransaminasemy $(4 \%)$, neutropenia $(10 \%)$. Triplet $\mathrm{FIr} / \mathrm{FOx}$, even associated to bevacizumab, determined only $10 \%$ G3-4 neutropenia, while FOLFOXIRI schedule, added or not to bevacizumab [26, 27], prevalently induced it (50\%, equivalently) and also febrile neutropenia ( $6 \%$ and $8.8 \%$, respectively) [30, $31]$. In the phase III trial proposing FOLFIRINOX [24] (OXP $85 \mathrm{mg} / \mathrm{m}^{2}$, CPT-11 $180 \mathrm{mg} / \mathrm{m}^{2}$, leucovorin 400 $\mathrm{mg} / \mathrm{m}^{2}$, and 5 -FU $400 \mathrm{mg} / \mathrm{m}^{2}$ as bolus followed by 2400 $\mathrm{mg} / \mathrm{m}^{2}$ as 46 -hour continuous infusion, every 2 weeks), the safety profile was less favourable than that reported in the gemcitabine arm [25]. More adverse events were reported in the FOLFIRINOX group: febrile neutropenia $5.4 \%$; grade 3-4 neutropenia $45.7 \%$, thrombocytopenia $9.1 \%$, diarrhea $12.7 \%$, and sensory neuropathy $9 \%$. Filgrastim was administered in $42.5 \%$ of patients who received FOLFIRINOX. The intensive biweekly schedule, addiction of leucovorin to 5-FU, bolus 5-FU administration, could explain the less favourable haematological toxicity profile, particularly in term of neutropenia and febrile neutropenia.

In the phase III trial, gemcitabine $1000 \mathrm{mg} / \mathrm{m}^{2}$ plus nab-paclitaxel $125 \mathrm{mg} / \mathrm{m}^{2}$ association, 3 out of 4 weeks [23], prevalent G3-4 adverse events were: neutropenia $(38 \%)$, febrile neutropenia (3\%), thrombocytopenia $(13 \%)$, anemia $(13 \%)$, asthenia $(17 \%)$, neurotoxicity $(17 \%)$, diarrhea (6\%). Granulocyte colony stimulating factor was administered in $26 \%$ of patients who received gemcitabine plus nab-paclitaxel. Dose modulations and treatment delays guaranteed more safely administration of gemcitabine and nab-paclitaxel association, and not significantly affected efficacy [40].

In the present study, LTS were observed in $27.5 \%$ of individual patients and in $38.4 \%$ of elderly patients treated with FIr/FOx regimen. The innovative clinical evaluation of LTS, consisting of at least the LT associated or not to other G2 or LT, introduced to better evaluate, in the individual patient, the presence of LT alone, LTSss, or the association of major toxicities in different sites, LTS-ms, showed that: overall, they were $3.4 \%$ and $24.1 \%$, respectively; among elderly patients, they were all LTS-ms $38.4 \%$. LTS were not significantly represented by LTS-ms compared to LTS-ss, even if the small number of enrolled patients requires further analyses. LTS-ms were mostly represented by diarrhea, mucositis, asthenia, neurotoxicity, thrombocytopenia and/or anemia, associated to nausea, vomiting, anorexia and/or neutropenia, hypokaliemia, hypoalbuminemia, hypertransaminasemia. In the individual patient, limiting and moderate toxicities often characterized LTS, previously observed in $44 \%$ MCRC patients treated with FIr-B/FOx, and equally involving single or multiple sites [27, 32].

Pharmacogenomic analysis evaluating 5-FU degradation rate (FUDR) and/or detection of a panel of DNA Single Nucleotide Polimorphisms (SNPs) involving different genes, such as DPYD, UGT1A1, ABCB1, CYP $3 A 4$, specifically influencing fluoropyrimidines and CPT-11-related adverse events, justifying interpatients variability in safety profile, may help selection of patients fit for triplet chemotherapy, and may predict the occurrence of individual LTS, prevalently gastrointestinal [34-36, 41, 42]. Their predictive role should be prospectively verified, to be used in clinical practice.

Reported data confirmed that intensive regimens, such as FIr/FOx, frequently required proper clinical management of toxicity and treatment modulations due to moderate/severe toxicities. Careful selection of eligible patients, based on age, PS, comorbidity index, and monitoring of individual safety, also according to LTS in individual patients, are major parameters to optimize clinical management of metastatic PDAC. More, close monitoring of patients, expertise with a particular regimen, and toxicity management, remained the physician-related factors, that can guide personalized selection of first-line regimens in individual PDAC patients. 
Table 6: Limiting Toxicity Syndromes (LTS)

\begin{tabular}{|c|c|c|c|c|}
\hline \multirow[t]{2}{*}{ Patients \# } & \multirow[t]{2}{*}{ Age (years) } & \multirow[t]{2}{*}{$\mathbf{L T}$} & \multicolumn{2}{|c|}{ Associated Toxicity } \\
\hline & & & LT & G2-G3 \\
\hline 4 & 61 & Diarrhea G3 & - & - \\
\hline 1 & 63 & Neurotoxicity G2 & - & $\begin{array}{c}\text { Nausea G2 } \\
\text { Vomiting G2 } \\
\text { Diarrhea G2 } \\
\text { Asthenia G2 } \\
\text { Neutropenia G2 }\end{array}$ \\
\hline 6 & 73 & Thrombocytopenia G2 & - & $\begin{array}{c}\text { Anemia G2 } \\
\text { Leuconeutropenia G3 } \\
\text { Ipokalemia G2 } \\
\text { Hypoalbuminemia G2 } \\
\text { Hypertransaminasemia G2 } \\
\text { Asthenia G2 } \\
\text { Anorexia G2 }\end{array}$ \\
\hline 16 & 66 & Thrombocytopenia G2 & - & $\begin{array}{c}\text { Diarrhea G2 } \\
\text { Neutropenia G2 } \\
\text { Alopecia G2 } \\
\text { Hypertransaminasemia G2 }\end{array}$ \\
\hline 23 & 76 & Asthenia G3 & - & $\begin{array}{c}\text { Alopecia G3 } \\
\text { Leuconeutropenia G3 }\end{array}$ \\
\hline 26 & 53 & Neurotoxicity G2 & - & $\begin{array}{c}\text { Nausea G2 } \\
\text { Diarrhea G2 } \\
\text { Constipation G2 } \\
\text { Alopecia G2 } \\
\text { Hypertransaminasemia G2 } \\
\text { Neutropenia G3 }\end{array}$ \\
\hline 28 & 72 & Diarrhea G3 & - & $\begin{array}{c}\text { Nausea G2 } \\
\text { Anorexia G2 }\end{array}$ \\
\hline 20 & 68 & Diarrhea G5 & $\begin{array}{c}\text { Mucositis G4 } \\
\text { Thrombocytopenia G4 } \\
\text { Anemia G3 }\end{array}$ & $\begin{array}{c}\text { Asthenia G2 } \\
\text { Hypoalbuminemia G3 } \\
\text { Hypokalemia G3 } \\
\text { Hypercreatininemia G3 } \\
\text { Leuconeutropenia G3 }\end{array}$ \\
\hline
\end{tabular}

Abbreviations: LT, limiting toxicity; G, grade.

\section{MATERIALS AND METHODS}

\section{Patient eligibility}

Patients were eligible if they had clinical and/ or histological/cytological confirmed diagnosis of measurable metastatic PDAC; age $\geq 18$ years, specifically $<65$ years (non-elderly), $\geq 65<75$ years (yE), and $\geq 75$ years $(\mathrm{oE})$; WHO PS $\leq 2$; adequate hematological, renal and hepatic functions; life expectancy more than 3 months.

Ineligibility criteria: pregnancy and breastfeeding; uncontrolled severe diseases; cardiovascular disease (uncontrolled hypertension, uncontrolled arrhythmia, ischemic cardiac diseases in the last year); thromboembolic disease, coagulopathy, pre-existing bleeding diatheses; sensory and/or motor polineuropathy; surgery within the previous 28 days; previous adjuvant chemotherapy or radiotherapy completed less than 6 months before. CIRS was used to evaluate the comorbidity status [37]. Primary CIRS stage consisted of: independent Instrumental Activity of Daily Living (IADL), and absent or mild grade comorbidities; intermediate CIRS stage consisted of dependent or independent IADL, and less than 3 mild or moderate grade comorbidities; secondary CIRS stage consisted of more than 3 comorbidities or a severe comorbidity, with or without dependent IADL.

Treatment was approved by Agenzia Italiana del Farmaco (AIFA) for administration in label for metastatic 
PDAC treatment in Italian public hospitals, and published in Gazzetta Ufficiale Repubblica Italiana ("Elenco dei Medicinali erogabili a totale carico del Servizio Sanitario Nazionale", Gazzetta Ufficiale Repubblica Italiana N.1, 2 Gennaio 2009). The study was approved by the Regional Review Board (Regione Abruzzo, Italia, according to D.G.R. n.489, 25/05/2007), and conducted in accordance with the Declaration of Helsinki. All patients provided written, informed consent.

\section{Methods}

\section{Schedule}

This was a single-arm phase II study evaluating safety and activity of weekly alternating 5-FU, CPT-11, and OXP (FIr/FOx) as first-line treatment of metastatic PDAC.

$\mathrm{FIr} / \mathrm{FOx}$ association consisted of 5-FU associated to alternating CPT-11 or OXP according to the following weekly schedule: TFI/5-FU (Fluorouracil Teva; Teva Italia, Milan, Italy), $750-800-900 \mathrm{mg} / \mathrm{m}^{2} /$ die, over 12 -hour (from 10:00 p.m to 10:00 a.m.), days $1-2,8-9,15-16$ and 22 23; CPT-11 (Campto; Pfizer, Latina, Italy), 120-140-160 $\mathrm{mg} / \mathrm{m}^{2}$, administered over 90 minutes as an intravenous infusion in $250 \mathrm{ml}$ of $\mathrm{NaCl} 0.9 \%$, days 1 and 15; OXP (Eloxatin; Sanofi-Aventis, Milan, Italy) over 2-hours as an intravenous infusion in $250 \mathrm{ml}$ of dextrose $5 \%$, at the dose of $70-80 \mathrm{mg} / \mathrm{m}^{2}$, days 8 and 22 . Cycles were repeated every 4 weeks. 5 -FU was administered by a portable pump (CADD Plus, SEVIT) using a venous access device. According to patients' fitness, and particularly in patients with PS 2 , and/or $\geq 75$ years, secondary CIRS stage, and/ or abnormal liver functional laboratory tests, such as $\geq$ G2 hypertransaminasemia at baseline, drugs' doses were modulated in individual patients as reported, providing a received DI $>75 \%$ for each drug, reported as active and efficacious in previous studies of triplet chemotherapy regimens [24, 26-31].

\section{Study design}

Physical examination and routine laboratory studies were performed at baseline and every week on-treatment, including complete blood cell count, electrolytes, liver and renal function tests, urine examination and coagulation function; tumor markers every cycle; electrocardiogram every cycle, and echocardiogram at baseline, and every 3 cycles.

Primary end-point was ORR; secondary end-points were toxicity, PFS, OS. ORR was evaluated according to RECIST criteria [43]; PFS and OS using Kaplan and Meier method [44]. PFS was defined as length of time between the beginning of treatment and disease progression or death (resulting from any cause) or to last contact; OS as length of time between the beginning of treatment and death or to last contact. The log-rank test was used to compare PFS and OS [45]. Clinical evaluation of response was made by computerized tomography (CT)-scan; magnetic resonance imaging (MRI) and/or positron emission tomography (PET) were added based on the investigators' assessment; objective responses were confirmed three months later. Follow-up was scheduled every three months, up to disease progression or death. Toxicity was monitored every week according to National Cancer Institute Common Toxicity Criteria (NCI-CTC, version 4.0). LT was defined as grade 3-4 non-haematological toxicity (mainly represented by diarrhea, mucositis, neurotoxicity, hand-foot syndrome, asthenia, liver functional tests), grade 4 hematologic toxicity, G4 neutropenia, febrile neutropenia, G3-4 thrombocytopenia, or associated with significant clinical bleeding, grade 3-4 anemia, G2-3 neurotoxicity, or any toxicity determining a $>2$ weeks treatment delay.

LTS, consisting of at least a LT associated or not to other limiting or G2 toxicities, were evaluated as previously reported $[27,32]$. These were classified as: LTS-ss, if characterized only by the LT; LTS-ms, if characterized by $\geq 2$ LTs or a LT associated to other, at least G2, non-limiting toxicities. Chi-square test was used to compared the rates of LTS-ms and LTS-ss [46].

Correlations between maximum decrease from baseline in CA19.9 level and PFS and OS were analyzed, to assess possible relationships between CA19.9 and clinical outcomes.

\section{Statistical design}

This phase II study was planned according to two-steps Simon's design [38]: assuming as minimal interesting activity an ORR 10\%, 1 objective response among the first 10 enrolled patients was necessary for the first-step; to verify the alternative hypothesis of ORR 30\%, 5 objective responses among the total 29 enrolled patients were necessary; power $(1-\beta) 80 \%$; error probability $\alpha 5 \%$. $\mathrm{p}_{0}$ was considered as the estimated activity reported with gemcitabine alone (median ORR $10 \%$ ), and confirmed with the association of gemcitabine plus erlotinib (ORR 8.6\%) $[1-5,16] ; p_{1}$ as the projected ORR using the present intensive triplet combination, according to FIr/FOx schedule, increasing the activity $\geq 20 \%$ in metastatic PDAC patients, as reported with FOLFIRINOX (ORR 31.6\%), and with the association of gemcitabine and nab-paclitaxel in the phase I/II trial (ORR $46 \%$ in the overall population, and $48 \%$ in patients treated at the recommended dose of nab-paclitaxel $125 \mathrm{mg} / \mathrm{m}^{2}$; ORR $23 \%$ in the more recently reported phase III trial) [22-24].

\section{CONCLUSIONS}

FIr/FOx intensive triplet chemotherapy in metastatic PDAC patients preliminary showed high activity. Present schedule was feasible in non-elderly and elderly patients, with PS 0-1, with manageable toxicities, at proper CPT-11, $\mathrm{OXP}$, and 5-FU doses. LTS were prevalently characterized 
by diarrhea, mucositis, asthenia, anemia, neurotoxicity and/or thrombocytopenia, associated to nausea, vomiting, anorexia and/or neutropenia. Elderly patients preliminary showed trendy, but not significantly worse OS. Adequate selection of suitable patients, based on clinical parameters, aimed to maintain safety profile at efficacious DIs, will verify if more intensive approaches, such as triplet chemotherapy regimen could increase OS, compared to historical gemcitabine control, in the clinical practice management of metastatic PDAC patients, and if it could be a treatment option in locally advanced/borderline resectable pancreatic cancer patients.

\section{Abbreviations}

CIRS: Cumulative Illness Rating Scale; CPT-11: irinotecan; DI: dose intensity; IADL: Instrumental Activity of Daily Living; LT: limiting toxicity; LTS: limiting toxicity syndromes; LTS-ms: limiting toxicity syndromes multiple sites; LTS-ss: limiting toxicity syndromes single site; MCRC: metastatic colorectal cancer; oE: old-elderly; OR: objective response; ORR: objective response rate; OS: overall survival; OXP: oxaliplatin; PDAC, pancreatic ductal adenocarcinoma; pDI: projected dose intensity; PFS: progression-free survival; PS, performance status; rDI: received dose intensity; TFI, timed-flat-infusion; yE: young-elderly; WHO: World Health Organization; 5-FU: 5-fluorouracil.

\section{Author contributions}

GB contributed to the conception and design of the study, in the provision of study materials of patients, in the data analysis and interpretation, in the manuscript writing. SM, EC contributed in schedule designing. RM, AVG, SC, ADS contributed in radiological evaluations. ER contributed to the conception and design of the study, in the data analysis and interpretation, in the manuscript writing. GB, SC, ER provided clinical management and data of patients. AG, AR contributed in the data analysis and interpretation. All authors participated in the collection and/or assembly of data. All authors read, revised and approved the final manuscript.

\section{CONFLICTS OF INTEREST}

The authors have declared that they have no conflicts of interest.

\section{REFERENCES}

1. Hidalgo M. Pancreatic cancer. N Engl J Med. 2010; 362:1605-17. https://doi.org/10.1056/NEJMra0901557.

2. Burris HA 3rd, Moore MJ, Andersen J, Green MR, Rothenberg ML, Modiano MR, Cripps MC, Portenoy RK, Storniolo AM, Tarassoff P, Nelson R, Dorr FA, Stephens CD, Von Hoff DD. Improvements in survival and clinical benefit with gemcitabine as first-line therapy for patients with advanced pancreas cancer: a randomized trial. J Clin Oncol. 1997; 15:2403-13. https://doi.org/10.1200/JCO.1997.15.6.2403.

3. Grunewald R, Abbruzzese JL, Tarassoff P, Plunkett W. Saturation of 2',2'-difluorodeoxycytidine 5'-triphosphate accumulation by mononuclear cells during a phase I trial of gemcitabine. Cancer Chemother Pharmacol. 1991; 27:25862. https://doi.org/10.1007/BF00685109.

4. Tempero M, Plunkett W, Ruiz Van Haperen V, Hainsworth J, Hochster H, Lenzi R, Abbruzzese J. Randomized phase II comparison of dose-intense gemcitabine: thirty-minute infusion and fixed dose rate infusion in patients with pancreatic adenocarcinoma. J Clin Oncol. 2003; 21:340208. https://doi.org/10.1200/JCO.2003.09.140.

5. Poplin E, Feng Y, Berlin J, Rothenberg ML, Hochster H, Mitchell E, Alberts S, O'Dwyer P, Haller D, Catalano P, Cella D, Benson AB 3rd. Phase III, randomized study of gemcitabine and oxaliplatin versus gemcitabine (fixeddose rate infusion) compared with gemcitabine (30-minute infusion) in patients with pancreatic carcinoma E6201: a trial of the Eastern Cooperative Oncology Group. J Clin Oncol. 2009; 27:3778-85. https://doi.org/10.1200/JCO.2008.20.9007.

6. Berlin JD, Catalano P, Thomas JP, Kugler JW, Haller DG, Benson AB 3rd. Phase III study of gemcitabine in combination with fluorouracil versus gemcitabine alone in patients with advanced pancreatic carcinoma: Eastern Cooperative Oncology Group Trial E2297. J Clin Oncol. 2002; 20:3270-75. https://doi.org/10.1200/JCO.2002.11.149.

7. Colucci G, Labianca R, Di Costanzo F, Gebbia V, Cartenì G, Massidda B, Dapretto E, Manzione L, Piazza E, Sannicolò M, Ciaparrone M, Cavanna L, Giuliani F, et al, and Gruppo Oncologico Italia Meridionale (GOIM), and Gruppo Italiano per lo Studio dei Carcinomi dell'Apparato Digerente (GISCAD), and Gruppo Oncologico Italiano di Ricerca Clinica (GOIRC). Randomized phase III trial of gemcitabine plus cisplatin compared with single-agent gemcitabine as first-line treatment of patients with advanced pancreatic cancer: the GIP-1 study. J Clin Oncol. 2010; 28:1645-51. https://doi.org/10.1200/JCO.2009.25.4433.

8. Cunningham D, Chau I, Stocken DD, Valle JW, Smith D, Steward W, Harper PG, Dunn J, Tudur-Smith C, West J, Falk $\mathrm{S}$, Crellin A, Adab F, et al. Phase III randomized comparison of gemcitabine versus gemcitabine plus capecitabine in patients with advanced pancreatic cancer. J Clin Oncol. 2009; 27:5513-18. https://doi.org/10.1200/JCO.2009.24.2446.

9. Heinemann V, Quietzsch D, Gieseler F, Gonnermann M, Schönekäs H, Rost A, Neuhaus H, Haag C, Clemens M, Heinrich B, Vehling-Kaiser U, Fuchs M, Fleckenstein $\mathrm{D}$, et al. Randomized phase III trial of gemcitabine plus cisplatin compared with gemcitabine alone in advanced pancreatic cancer. J Clin Oncol. 2006; 24:3946-52. https://doi.org/10.1200/JCO.2005.05.1490.

10. Herrmann R, Bodoky G, Ruhstaller T, Glimelius B, Bajetta E, Schüller J, Saletti P, Bauer J, Figer A, Pestalozzi B, Köhne 
$\mathrm{CH}$, Mingrone W, Stemmer SM, et al, and Swiss Group for Clinical Cancer Research, and Central European Cooperative Oncology Group. Gemcitabine plus capecitabine compared with gemcitabine alone in advanced pancreatic cancer: a randomized, multicenter, phase III trial of the Swiss Group for Clinical Cancer Research and the Central European Cooperative Oncology Group. J Clin Oncol. 2007; 25:221217. https://doi.org/10.1200/JCO.2006.09.0886.

11. Louvet C, Labianca R, Hammel P, Lledo G, Zampino MG, André T, Zaniboni A, Ducreux M, Aitini E, Taïeb J, Faroux R, Lepere C, de Gramont A, and GERCOR, and GISCAD. Gemcitabine in combination with oxaliplatin compared with gemcitabine alone in locally advanced or metastatic pancreatic cancer: results of a GERCOR and GISCAD phase III trial. J Clin Oncol. 2005; 23:3509-16. https://doi.org/10.1200/JCO.2005.06.023.

12. Reni M, Cordio S, Milandri C, Passoni P, Bonetto E, Oliani C, Luppi G, Nicoletti R, Galli L, Bordonaro R, Passardi A, Zerbi A, Balzano G, et al. Gemcitabine versus cisplatin, epirubicin, fluorouracil, and gemcitabine in advanced pancreatic cancer: a randomised controlled multicentre phase III trial. Lancet Oncol. 2005; 6:369-76. https://doi.org/10.1016/S1470-2045(05)70175-3.

13. Rocha Lima CM, Green MR, Rotche R, Miller WH Jr, Jeffrey GM, Cisar LA, Morganti A, Orlando N, Gruia G, Miller LL. Irinotecan plus gemcitabine results in no survival advantage compared with gemcitabine monotherapy in patients with locally advanced or metastatic pancreatic cancer despite increased tumor response rate. J Clin Oncol. 2004; 22:377683. https://doi.org/10.1200/JCO.2004.12.082.

14. Kulke MH, Tempero MA, Niedzwiecki D, Hollis DR, Kindler HL, Cusnir M, Enzinger PC, Gorsch SM, Goldberg RM, Mayer RJ. Randomized phase II study of gemcitabine administered at a fixed dose rate or in combination with cisplatin, docetaxel, or irinotecan in patients with metastatic pancreatic cancer: CALGB 89904. J Clin Oncol. 2009; 27:5506-12. https://doi.org/10.1200/JCO.2009.22.1309.

15. Stathopoulos GP, Syrigos K, Aravantinos G, Polyzos A, Papakotoulas P, Fountzilas G, Potamianou A, Ziras N, Boukovinas J, Varthalitis J, Androulakis N, Kotsakis A, Samonis G, Georgoulias V. A multicenter phase III trial comparing irinotecan-gemcitabine (IG) with gemcitabine $(\mathrm{G})$ monotherapy as first-line treatment in patients with locally advanced or metastatic pancreatic cancer. Br J Cancer. 2006; 95:587-92. https://doi.org/10.1038/sj.bjc.6603301.

16. Moore MJ, Goldstein D, Hamm J, Figer A, Hecht JR, Gallinger S, Au HJ, Murawa P, Walde D, Wolff RA, Campos D, Lim R, Ding K, et al, and National Cancer Institute of Canada Clinical Trials Group. Erlotinib plus gemcitabine compared with gemcitabine alone in patients with advanced pancreatic cancer: a phase III trial of the National Cancer Institute of Canada Clinical Trials Group. J Clin Oncol. 2007; 25:1960-66. https://doi.org/10.1200/JCO.2006.07.9525.

17. Heinemann V, Boeck S, Hinke A, Labianca R, Louvet C. Meta-analysis of randomized trials: evaluation of benefit from gemcitabine-based combination chemotherapy applied in advanced pancreatic cancer. BMC Cancer. 2008; 8:82. https://doi.org/10.1186/1471-2407-8-82.

18. Kindler HL, Friberg G, Singh DA, Locker G, Nattam S, Kozloff M, Taber DA, Karrison T, Dachman A, Stadler WM, Vokes EE. Phase II trial of bevacizumab plus gemcitabine in patients with advanced pancreatic cancer. J Clin Oncol. 2005; 23:8033-40. https://doi.org/10.1200/JCO.2005.01.9661.

19. Xiong HQ, Rosenberg A, LoBuglio A, Schmidt W, Wolff RA, Deutsch J, Needle M, Abbruzzese JL. Cetuximab, a monoclonal antibody targeting the epidermal growth factor receptor, in combination with gemcitabine for advanced pancreatic cancer: a multicenter phase II Trial. J Clin Oncol. 2004; 22:2610-16. https://doi.org/10.1200/JCO.2004.12.040.

20. Kindler HL, Niedzwiecki D, Hollis D, Sutherland S, Schrag D, Hurwitz H, Innocenti F, Mulcahy MF, O'Reilly E, Wozniak TF, Picus J, Bhargava P, Mayer RJ, et al. Gemcitabine plus bevacizumab compared with gemcitabine plus placebo in patients with advanced pancreatic cancer: phase III trial of the Cancer and Leukemia Group B (CALGB 80303). J Clin Oncol. 2010; 28:3617-22. https://doi.org/10.1200/JCO.2010.28.1386.

21. Van Cutsem E, Vervenne WL, Bennouna J, Humblet Y, Gill S, Van Laethem JL, Verslype C, Scheithauer W, Shang A, Cosaert J, Moore MJ. Phase III trial of bevacizumab in combination with gemcitabine and erlotinib in patients with metastatic pancreatic cancer. J Clin Oncol. 2009; 27:223137. https://doi.org/10.1200/JCO.2008.20.0238.

22. Von Hoff DD, Ramanathan RK, Borad MJ, Laheru DA, Smith LS, Wood TE, Korn RL, Desai N, Trieu V, Iglesias JL, Zhang H, Soon-Shiong P, Shi T, et al. Gemcitabine plus nab-paclitaxel is an active regimen in patients with advanced pancreatic cancer: a phase I/II trial. J Clin Oncol. 2011; 29:4548-54. https://doi.org/10.1200/JCO.2011.36.5742.

23. Von Hoff DD, Ervin T, Arena FP, Chiorean EG, Infante J, Moore M, Seay T, Tjulandin SA, Ma WW, Saleh $\mathrm{MN}$, Harris $\mathrm{M}$, Reni $\mathrm{M}$, Dowden $\mathrm{S}$, et al. Increased survival in pancreatic cancer with nab-paclitaxel plus gemcitabine. N Engl J Med. 2013; 369:1691-703. https://doi.org/10.1056/NEJMoa1304369.

24. Conroy T, Desseigne F, Ychou M, Bouché O, Guimbaud R, Bécouarn Y, Adenis A, Raoul JL, Gourgou-Bourgade S, de la Fouchardière $\mathrm{C}$, Bennouna $\mathrm{J}$, Bachet JB, Khemissa-Akouz F, et al, and Groupe Tumeurs Digestives of Unicancer, and PRODIGE Intergroup. FOLFIRINOX versus gemcitabine for metastatic pancreatic cancer. N Engl J Med. 2011; 364:181725. https://doi.org/10.1056/NEJMoa1011923.

25. Gourgou-Bourgade S, Bascoul-Mollevi C, Desseigne F, Ychou M, Bouché O, Guimbaud R, Bécouarn Y, Adenis A, Raoul JL, Boige V, Bérille J, Conroy $\mathrm{T}$. Impact of FOLFIRINOX compared with gemcitabine on quality of life in patients with metastatic pancreatic cancer: results from the PRODIGE 4/ACCORD 11 randomized trial. J Clin Oncol. 2013; 31:23-29. https://doi.org/10.1200/JCO.2012.44.4869. 
26. Morelli MF, Santomaggio A, Ricevuto E, Cannita K, De Galitiis F, Tudini M, Bruera G, Mancini M, Pelliccione M, Calista F, Guglielmi F, Martella F, Lanfiuti Baldi P, et al. Triplet schedule of weekly 5-fluorouracil and alternating irinotecan or oxaliplatin in advanced colorectal cancer: a dose-finding and phase II study. Oncol Rep. 2010; 23:1635-40.

27. Bruera G, Santomaggio A, Cannita K, Baldi PL, Tudini M, De Galitiis F, Mancini M, Marchetti P, Antonucci A, Ficorella C, Ricevuto E. "Poker" association of weekly alternating 5-fluorouracil, irinotecan, bevacizumab and oxaliplatin (FIr-B/FOx) in first line treatment of metastatic colorectal cancer: a phase II study. BMC Cancer. 2010; 10:567. https://doi.org/10.1186/1471-2407-10-567.

28. Falcone A, Ricci S, Brunetti I, Pfanner E, Allegrini G, Barbara C, Crinò L, Benedetti G, Evangelista W, Fanchini L, Cortesi E, Picone V, Vitello S, et al, and Gruppo Oncologico Nord Ovest. Phase III trial of infusional fluorouracil, leucovorin, oxaliplatin, and irinotecan (FOLFOXIRI) compared with infusional fluorouracil, leucovorin, and irinotecan (FOLFIRI) as first-line treatment for metastatic colorectal cancer: the Gruppo Oncologico Nord Ovest. J Clin Oncol. 2007; 25:1670 76. https://doi.org/10.1200/JCO.2006.09.0928.

29. Loupakis F, Cremolini C, Masi G, Lonardi S, Zagonel V, Salvatore L, Cortesi E, Tomasello G, Ronzoni M, Spadi R, Zaniboni A, Tonini G, Buonadonna A, et al. Initial therapy with FOLFOXIRI and bevacizumab for metastatic colorectal cancer. N Engl J Med. 2014; 371:1609-18. https://doi.org/10.1056/NEJMoa1403108.

30. Bruera G, Ricevuto E. Intensive chemotherapy of metastatic colorectal cancer: weighing between safety and clinical efficacy: Evaluation of Masi G, Loupakis F, Salvatore L, et al. Bevacizumab with FOLFOXIRI (irinotecan, oxaliplatin, fluorouracil, and folinate) as first-line treatment for metastatic colorectal cancer: a phase 2 trial. Lancet Oncol 2010;11:845-52. Expert Opin Biol Ther. 2011; 11:821-4. https://doi.org/10.1517/14712598.2011.582462.

31. Ficorella C, Bruera G, Cannita K, Porzio G, Baldi PL, Tinari N, Natoli C, Ricevuto E. Triplet chemotherapy in patients with metastatic colorectal cancer: toward the best way to safely administer a highly active regimen in clinical practice. Clin Colorectal Cancer. 2012; 11:229-37. https://doi.org/10.1016/j.clcc.2012.05.001.

32. Bruera G, Cannita K, Giordano AV, Vicentini R, Ficorella $\mathrm{C}$, Ricevuto E. Effectiveness and safety of intensive triplet chemotherapy plus bevacizumab, FIr-B/FOx, in youngelderly metastatic colorectal cancer patients. Biomed Res Int. 2013; 2013:143273. https://doi.org/10.1155/2013/143273.

33. Bruera G, Russo A, Galvano A, Rizzo S, Ricevuto E. Clinical parameters to guide decision-making in elderly metastatic colorectal CANCER patients treated with intensive cytotoxic and anti-angiogenic therapy. Oncotarget. 2017; 8:37875-83. https://doi.org/10.18632/oncotarget.14333.

34. Evaluation of Genomic Applications in Practice and Prevention (EGAPP) Working Group. Recommendations from the EGAPP Working Group: can UGT1A1 genotyping reduce morbidity and mortality in patients with metastatic colorectal cancer treated with irinotecan? Genet Med. 2009; 11:15-20. https://doi.org/10.1097/GIM.0b013e31818efd9d.

35. Satoh T, Ura T, Yamada Y, Yamazaki K, Tsujinaka T, Munakata M, Nishina T, Okamura S, Esaki T, Sasaki Y, Koizumi W, Kakeji Y, Ishizuka N, et al. Genotype-directed, dose-finding study of irinotecan in cancer patients with UGT1A1*28 and/or UGT1A1*6 polymorphisms. Cancer Sci. 2011; 102:1868-73. https://doi.org/10.1111/j.1349-7006.2011.02030.x.

36. Takano M, Goto T, Hirata J, Furuya K, Horie K, Takahashi M, Yokota H, Kino N, Kudoh K, Kikuchi Y. UGT1A1 genotype-specific phase I and pharmacokinetic study for combination chemotherapy with irinotecan and cisplatin: a Saitama Tumor Board study. Eur J Gynaecol Oncol. 2013; 34:120-23.

37. Extermann M, Overcash J, Lyman GH, Parr J, Balducci L. Comorbidity and functional status are independent in older cancer patients. J Clin Oncol. 1998; 16:1582-87. https://doi.org/10.1200/JCO.1998.16.4.1582.

38. Simon R. Optimal two-stage designs for phase II clinical trials. Control Clin Trials. 1989; 10:1-10. https://doi.org/10.1016/0197-2456(89)90015-9.

39. Tabernero J, Chiorean EG, Infante JR, Hingorani SR, Ganju V, Weekes C, Scheithauer W, Ramanathan RK, Goldstein D, Penenberg DN, Romano A, Ferrara S, Von Hoff DD. Prognostic factors of survival in a randomized phase III trial (MPACT) of weekly nab-paclitaxel plus gemcitabine versus gemcitabine alone in patients with metastatic pancreatic cancer. Oncologist. 2015; 20:14350. https://doi.org/10.1634/theoncologist.2014-0394.

40. Goldstein D, El-Maraghi RH, Hammel P, Heinemann V, Kunzmann V, Sastre J, Scheithauer W, Siena S, Tabernero J, Teixeira L, Tortora G, Van Laethem JL, Young $\mathrm{R}$, et al. nab-Paclitaxel plus gemcitabine for metastatic pancreatic cancer: long-term survival from a phase III trial. J Natl Cancer Inst. 2015; 107:107. https://doi.org/10.1093/jnci/dju413.

41. Falvella FS, Cheli S, Martinetti A, Mazzali C, Iacovelli R, Maggi C, Gariboldi M, Pierotti MA, Di Bartolomeo M, Sottotetti E, Mennitto R, Bossi I, de Braud F, et al. DPD and UGT1A1 deficiency in colorectal cancer patients receiving triplet chemotherapy with fluoropyrimidines, oxaliplatin and irinotecan. Br J Clin Pharmacol. 2015; 80:581-88. https://doi.org/10.1111/bcp.12631.

42. Dias MM, McKinnon RA, Sorich MJ. Impact of the UGT1A $1 * 28$ allele on response to irinotecan: a systematic review and meta-analysis. Pharmacogenomics. 2012; 13:889-99. https://doi.org/10.2217/pgs.12.68.

43. Therasse P, Arbuck SG, Eisenhauer EA, Wanders J, Kaplan RS, Rubinstein L, Verweij J, Van Glabbeke M, van Oosterom AT, Christian MC, Gwyther SG. New guidelines to evaluate the response to treatment in solid tumors. European Organization for Research and Treatment of 
Cancer, National Cancer Institute of the United States, National Cancer Institute of Canada. J Natl Cancer Inst. 2000; 92:205-16

44. Kaplan EL, Meier P. Nonparametric estimation of incomplete observations. J Am Stat Assoc. 1958; 53:45781. https://doi.org/10.1080/01621459.1958.10501452.
45. Peto R, Peto J. Asymptomatically efficient rank invariant test procedures. J R Stat Soc Ser A 1972; 135:185-206. https://doi.org/10.2307/2344317.

46. Mantel N. Chi-square tests with one degree of freedom: extensions of the Mendel-Haenszel procedure. J Am Stat Assoc. 1963; 58:690-700. 